\title{
Döner Kanatı İnsansız Hava Aracının Sistem Tasarımı ve Kontrolü
}

\author{
Tuğrul Oktay ${ }^{1}$, Enes Özen ${ }^{2 *}$ \\ ${ }^{1}$ Erciyes Üniversitesi, Havacılık ve Uzay Bilimleri Fakültesi, Uçak Mühendisliği Bölümü, Kayseri, Türkiye (ORCID: 0000-0003-4860-2230), oktay@ercityes.edu.tr \\ $2^{2^{*}}$ Hasan Kalyoncu Üniversitesi, Meslek Yüksekokulu, İHA Teknolojisi ve Operatörlüğü Programı, Gaziantep, Türkiye (ORCID: 0000-0001-7816-2374), \\ enes.ozen@hku.edu.tr
}

(İlk Geliş Tarihi 24 Haziran 2021 ve Kabul Tarihi 9 Eylül 2021)

(DOI: 10.31590/ejosat.957056)

\begin{abstract}
ATIF/REFERENCE: Oktay, T., Özen, E. (2021). Döner Kanatlı İnsansız Hava Aracının Sistem Tasarımı Ve Kontrolü. Avrupa Bilim ve Teknoloji Dergisi, (27), 318-324.
\end{abstract}

$\ddot{\mathbf{O} z}$

Hava araçları insanlı ve insansız olarak iki kategoride sınıflandırılır. İnsansız hava araçları arama, kurtarma, araştırma, gözlemleme gibi görevler için tercih edilmektedir. Taşıyabileceği faydalı yük, uçuş süresi gibi durumlar hava aracının tasarımında limitler oluşmasına sebep olmaktadır. Geleneksel hava araçlarının seyir edemediği alanlara nüfuz edebilecek ve aynı faydalı yük kapasitesinde hava araçlarına ihtiyaç olmuştur. Bu ihtiyaç, doğadaki kuşların incelemeleri sonucunda şekil değiştirebilen sistemlerin uygulanabilirliği araştırmalara konu olmuştur. Bu çalışmada dört rotorlu insansız hava aracı ile aynı faydalı yük kapasitesi ve aynı uçuş süresine sahip şekil değiştirebilen dört rotorlunun sistem tasarımı ve kontrolü gerçekleştirildi. Kararsız yapıda olan dört rotorlu PID (oransal integral türev) kontrolör ile kontrol edilebildi. Hava aracı üzerinde bulundurduğu MEMS (Mikro Elektro-Mekanik Sensör)'ler ve engel algılama sensörleri sayesinde dört rotorlunun kolları arasındaki kesişim açısını değiştirecek aktüatörün enerjilendirilmesi ile açı azaltılarak kapalı ortamda engellerden sakınması ve seyrine devam edebilmesi amaçlandı. Hava aracının seyir halinde şekil değiştirmesi neticesinde meydana gelen konfigürasyon değişikliğinin uçuş karakteristiğine olan etkileri incelendi. Elde edilen bu sonuçlar, bu çalışma kapsaminda sunuldu.

\section{System Design and Control of Rotary Wing Unmanned Aerial Vehicle}

\begin{abstract}
Aircraft are classified in two categories as manned and unmanned. Unmanned aerial vehicles are preferred for tasks such as search, rescue, research and observation. Conditions such as the payload it can carry and the flight time cause limits in the design of the aircraft. There was a need for aircraft with the same payload capacity that could penetrate areas where conventional aircraft could not navigate. This need and the applicability of systems that can change shape as a result of the studies of birds in nature have been the subject of research. In this study, the system design and control of a morphing quadrotor with the same payload capacity and the same flight time as the quadrotor unmanned aerial vehicle was carried out. It could be controlled with a PID controller, which is unstable. Thanks to the MEMS and obstacle detection sensors on the aircraft, it is aimed to energize the actuator, which will change the angle of intersection between the arms of the quadrotor, and to avoid obstacles in the closed environment and continue its course by reducing the angle. The effects of the configuration change, which occurred as a result of the shape change of the aircraft while cruising, on the flight characteristics were examined. These results are presented within the scope of this study.
\end{abstract}

Keywords: Morhing Quadrotor, MEMS, System Design, System Control.

\footnotetext{
* Sorumlu Yazar: enes.ozen@hku.edu.tr
} 


\section{Giriş}

Hava araçları, taşıdıkları faydalı yükler sayesinde birçok görevi yerine getirebilmektedir. Bunlardan en önemlisi arama kurtarma görevidir. Gerçekleşen deprem, yangın veya rehin alma gibi durumlarda, kapalı alanlarda hareket kabiliyeti yüksek aynı zamanda taşıdığ faydalı yükler sayesinde verilen görevleri doğru bir şeklide gerçekleştirmesi arzu edilmektedir. Gelişen teknoloji ile birlikte yüksek çözünürlüklü sensörler hava araçlarında uygulanmaktadır. Sensörlerden alınan yüksek hassasiyetteki veriler, hava aracının kör uçuş gerçekleştirebilmesini sağlamaktadır. Bu uygulamalar için en uygun hava aracı dört rotorlu insansız hava araçlarıdır. Günümüzde yaygın olarak kullanılan dört rotorlu hava araçları, kapalı ortam uygulamaları için yeteri kadar ergonomik değildir. Dış ortamda atmosferik bozuntulara karşı uçuş kararlılığını koruyabilecek şekilde geliştirilen dört rotorlu hava aracı, kapalı ortamlarda engellerden sakınmak için yeteri kadar küçük değildir. Dış ortamlarda, belirtilen durumlarda kararlı uçabilen aynı zamanda kapalı ortamlarda da uçuş gerçekleştirebilen döner kanatlı hava araçlarına ihtiyaç vardır. Şekil değiştirebilen kuadrotorda, kolları arasındaki kesişim açısı, kontrol edebilen mekanizma sayesinde değiştirebilmektedir.

A. Desbiez et al. [1] çalışmalarında X-Morf robotu ile yapılan testler, uçuş sırasında genişliğini 0,5 saniye içinde $\% 28,5^{\prime}$ 'e kadar dinamik olarak azaltabildiğini ve artırabildiğini, aynı zamanda iyi stabilite ve tutum izleme performansları sağladığını gösterdi.

Falanga, D. et al. [2] çalışmalarında uçuş sırasında aracın şeklini belirli bir göreve veya ortama uyacak şekilde değiştirmekten oluşan uyarlanabilir bir morfolojinin kullanımını araştırdı.

Y. Bai ve S. Gururajan [3] çalışmalarında uçuş sırasında kesişme açısını değiştirebilen bir morphing geometrili quadcopter'ın tasarımını, imalatını ve uçuş testi değerlendirmesini açıklamaktadır.

Di Luca M. et al.[4] çalışmalarında, farklı aerodinamik gereksinimleri karşılamak için geometrisini hızla değiştirebilen yapay tüylerden oluşan yeni bir morphing kanat tasarımı gerçekleştirdiler.

Prisacariu, V., Sandru, V., ve Rău, C. [5] çalışmalarında otomatik komuta kontrol sisteminin kökenini, tarihçesini ve dönüşen İHA türlerini ve konseptine dayalı ilkelerini incelemektedir.

Oktay, T., \& Sal, F [6] çalışmalarında daha fazla helikopter uçuş kontrol sistemi (yani FCS) enerjisinden tasarruf etmek için pasif geçiş ve aktif geçiş yaklaşımları birleştirilmiştir.

O. Kose ve T. Oktay [7] çalışmalarında quadrotorların yaw hareketi için eş zamanlı olmayan morphing tasarımı yapmışlardır. Çalışmalarında quadrotor dinamik modellemesini durum uzay modeli kullanarak Matlab/Simulink ortamında geliştirmişlerdir.

O. Kose ve T. Oktay [8] çalışmalarında boylamasına, yanlamasına ve hover uçuşu için bir quadrotor tasarımı yapmışlardır. Çalışmalarında Newton-Euler metodu ile quadrotor dinamiklerini türetmişler ve lineer modelleme üzerinde çalışmışlardır.

O. Kose ve T. Oktay [9] çalışmalarında quadrotorların için eş zamanlı olmayan morphing tasarımı gerçekleştirmişlerdir. Yazarlar Solidworks programında quadrotor morphing olan ve olmayan durumlarını tam model olarak çizmişlerdir. Çizilen modellerde katı cisim dinamiklerinden yararlanılarak morphing olmayan ve olan durumlarda quadrotor atalet parametrelerini elde etmişlerdir. Atalet parametreleri ise durum uzay modeli yaklaşımında giriş matrisi elemanı olarak değişkenlik gösterdiğini ifade etmişlerdir. Değişen atalet parametreleri ve PID kontrol algoritmasını kullanarak boylamasına ve yanlamasına uçuş için simülasyonlar yapmışlardır.

J. Zhang, J. Feng, B. Zhou. Sensor [10] çalışmalarında, MEMS IMU'ların hatalarını ortadan kaldırmak ve quadrotor dronların yörüngesini yeniden oluşturmak için yeni bir sensörfüzyon tabanlı yöntem öneriyoruz. MEMS IMU'lar, dört rotorlu dronlarda ve diğer mobil cihazlarda yaygın olarak donatılmıştır. Ne yazık ki, yörünge rekonstrüksiyonunda kötü sonuçlara neden olan birçok doğal hata taşırlar. Bu sorunu çözmek için MEMS IMU'lardaki ivmeölçer sinyalleri için bir hata modeli kurulmuştur. $\mathrm{Bu}$ modelde hata, bir önyargı bileşeni ve bir gürültü bileşeninden oluşur. İlk olarak, gürültü bileşenini azaltmak için alt örneklemeli bir alçak geçiren filtre uygulanır. Ardından, önyargı bileşeni, diğer sensörlerin yardımıyla dinamik olarak algılanır ve ortadan kaldırılır. Son olarak, dronun yörüngesi, kalibre edilmiş ivmeölçer verilerinin entegrasyonu yoluyla yeniden yapılandırılır. Yörünge yeniden yapılandırma yöntemimizi, düşük maliyetli bir MEMS IMU kullanan Parrot AR.Drone 2.0 üzerinde uyguluyoruz. Deneysel sonuçlar etkinliğini kanıtlıyor. Bu yöntem teorik olarak MEMS IMU'ları ile donatılmış diğer mobil cihazlara uygulanabilir.

Bu çalışmada, daha önce yapılan çalışmalardan elde edilen kazanımlarla şekil değiştebilen kuadrotor tasarımı gerçekleştirildi. Şekil değişikliği durumunda kontrol edilebilirliği incelendi. Sensörlerden alınan veriler sayesinde kapalı ortamda karar verebilme yeteneği kuadrotora kazandırıldı.

\section{Materyal ve Yöntem}

Bu çalışmada arama ve kurtarma görevleri için otonom döner kanatlı insansız hava aracı tasarlandı. Döner kanatlı insansız hava aracının avantajı dikey iniş kalkış yapabilmesi ve askıda kalabilmesidir. Böylelikle kapalı alanlarda düşük hızlarda uçuş gerçekletirebilmekte üzerinde bulundurduğu sensörler sayesinde engellerden sakınabilmektedir. Yavaş hızda uçabilmesi ve askıda kalabilmesinin yanında kaldırma kuvveti pervaneler tarafindan üretildiği için enerji kaybı fazladır. Güç tüketimi bununla doğru orantılı olup havada kalma süresi kısıtlıdır. Daha uzun havada kalma süresi için daha fazla bataryaya ihtiyaç vardır. Bu da uçuş ağrılığını artırmaktadır. Daha fazla yük, daha büyük pervanelere olan ihtiyacı artırmaktadır. Görev amacı göz önüne alındığında kapalı ortamlarda engellerden sakınması ve dar yerlerden geçebilmesi için gövdenin yanal olarak daralabilmesi fonksiyonu hava aracına eklendi. Aktif olarak şekil değiştirebilen hava aracı $\mathrm{X} 1$ ve X2 iki farklı konfigürasyon da uçuş gerçekleştirebilmektedir.

Hava aracının kabiliyetleri genişledikçe, yönlendirme ve navigasyon sistemlerini oluşturan donanım ve yazılıma talepler de artmaktadır. Rehberlik, seyrüsefer ve kontrol algoritmaları, hava aracının otonom uçuş yoluyla atanan görevi başarıyla tamamlamak için uçuş yazılımının temelini oluşturur. Hava aracının kapalı ortamlarda gerçekleştireceği görev için otonom rehberlik, navigasyon ve kontrolcüye ihtiyaç vardır [13]. Kuadrotordaki rehberlik, navigasyon ve kontrol sisteminin diyagramı Şekil 1'de gösterilmektedir. 


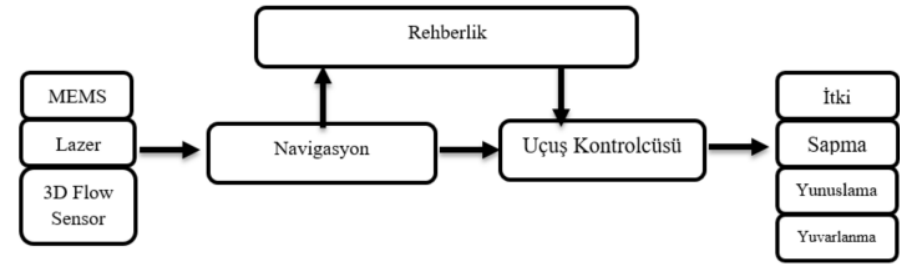

\section{Şekil 1. Kontrol Sistem Diyagramı}

Hava aracının tehlikeli ve karmașık ortamları incelemek ve keşfetmek gibi artan sayıda sivil ve askeri uygulamaya rastlanmaktadır. Bu görevleri doğrudan veya sürekli insan kontrolü olmadan gerçekleştirmek için otonom rehberlik, navigasyon ve kontrol gereklidir. Kontrol sistemi, hava aracını istenen konuma yönlendiren rehberlik sistemi, mevcut konumunu izleyen ve durumunu tahmin eden navigasyon sistemi ve rehberlik komutlarını kabul eden ve rehberlik hedeflerini takip etmek ve aynı zamanda hava aracı tutumunu dengelemek için gerçek aktüatör sinyallerini üretmek için navigasyon verilerini kullanan kontrol döngüsü tasarımı gerekmektedir [13].

\subsection{Döner Kanatı Hava Aracı Tasarımı}

Döner kanatlı insansız hava aracı, rotorların pervaneleri döndürmesiyle elde edilen kaldırma kuvveti ile havalanmaktadır. Rotorun farklı hızlarda dönmesi hava aracının merkezindeki gövde eksen takımında gerçekleştirilen rotasyon hareketleri, yatay veya dikey eksende hareket etmesini sağlamaktadır. Rotorların açısal hızlarındaki bu değişimi uçuş kontrolcüsü tarafından sensörlerden ve komutların derlenmesiyle gerekli yönelmenin sağlanması için rotorlara sinyal iletir [16]. Dört rotorlu insansız hava aracının motor yerleşim ve dönüş yönlerini belirleyen konfigürasyon bilgisi önemlidir. İki çeşit konfigürasyon bulunmakta ve bunlar artı (Şekil 2a) ve çarpraz (Şekil 2b) konfigürasyonlardır. Bu çalışmada $\mathrm{X}$ konfigürasyon tercih edildi.

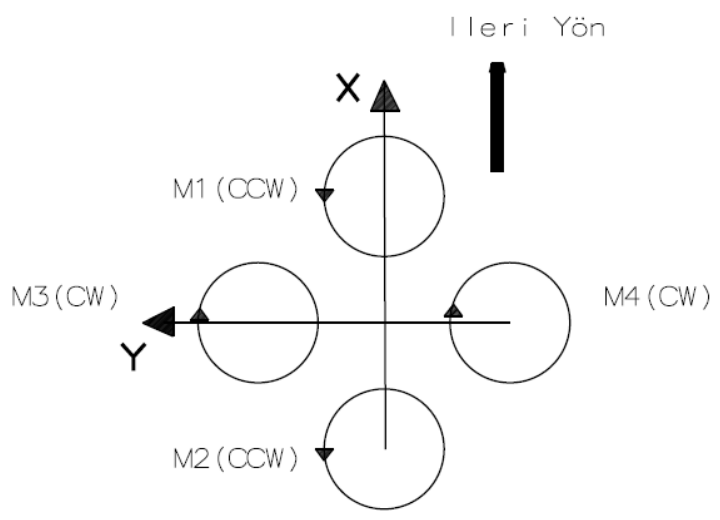

Şekil 2a. Dört Rotorlu Insansız Hava Aracı + Konfigurasyon

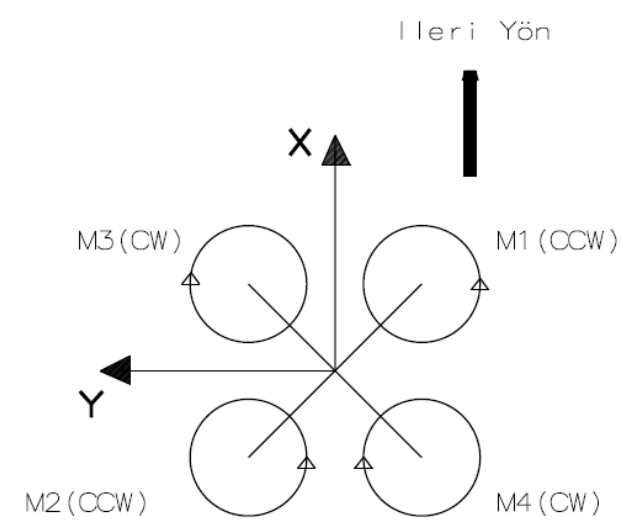

Şekil 2b. Dört Rotorlu İnsansız Hava Aracı X Konfigurasyon

Rotorlar sırayla ters yönde dönüş gerçekleştirmelidir. $\mathrm{Bu}$ sayede pervanelerin ürettiği sürükleme kuvveti etkisiyle platformun düşey eksen etrafinda oluşan toplam moment dengelenir. $\mathrm{Bu}$ yüzden kullanılan rotor ve pervaneler eşdeğer seçilmelidir. X ekseninin sağındaki veya solundaki rotorlar hangi yöne yatış hareketi gerçekleştirilecekse bunun zıttı bölgedeki rotorların dönüş hızları artırılır. Bu sayede eksen etrafinda kuvvet farkı oluşturulur. X ekseni etrafında moment oluşur. Bu da yatışın gerçekleştirilmesini sağlar. Yatış sırasında pervanelerin dikey eksen ile arasında oluşan açı net itkinin azalmasına sebep olacaktır. Bu durum askıda kalma durumuna göre kuadrotorun daha fazla güç tüketmesine sebep olacaktır. Benzer durum sapma ve yunuslama hareketleri içinde geçerlidir.

Kapalı ortamlarda hava aracinın hareket edebilmesi engellerden sakınması ve dar alanlardan geçebilmesi gerekebilir. Bunun için optimizasyon çalışması yapılabilir veya bu çalışmada olduğu gibi hava aracının aktif şekil değiştirmesi sağlanabilir [6]. Hava aracı, iki kol ve bunlara monte edilmiş rotor ve pervanelerin dönmesi etkisiyle aerodinamik kuvvetleri oluşturmaktadır. Bu kollar arasındaki açı bir mekanizma tarafından değiştirilebilir. $\mathrm{Bu}$ değişiklik sonucunda hava aracının gövde ölçüleri Tablo 1'de verildi.

Tablo 1. Dört rotorlu Hava Aracl Geometrisi

\begin{tabular}{|l|l|l|}
\hline $\begin{array}{l}\text { Hava Arac1 } \\
\text { Ölçüler }\end{array}$ & X1 Konfigurasyon & X2 Konfigurasyon \\
\hline Genişlik & $578 \mathrm{~mm}$ & $432 \mathrm{~mm}$ \\
\hline Boy & $578 \mathrm{~mm}$ & $675 \mathrm{~mm}$ \\
\hline
\end{tabular}

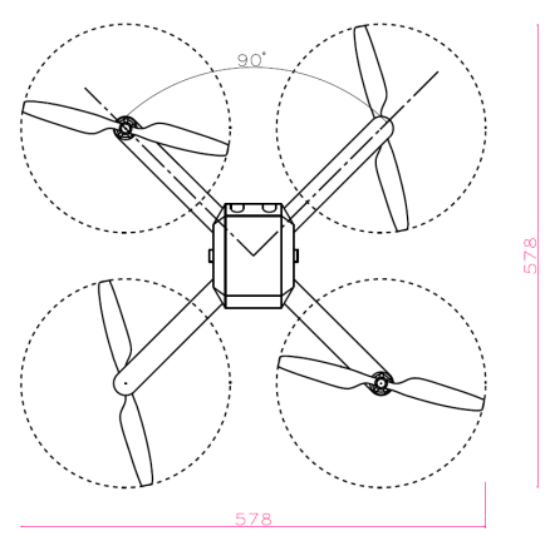

Şekil 3. X1 Konfigurasyon Kesişme Açısı 90 (Şekil Değişimi Olmadan) 


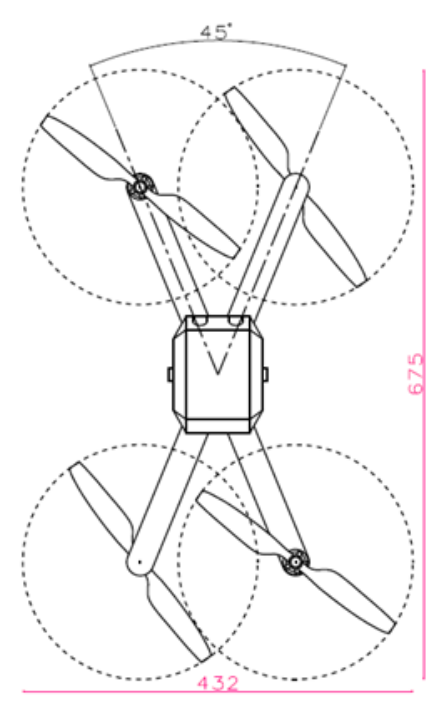

Şekil 4. X2 Konfigurasyon Kesişme Açısı 45 ( Yanal Daralmış)

Hava aracının kolları arasındaki bu değişim sistemin ağırlık merkezini etkilememektedir. Rotorların ağırlık merkezine olan uzaklığı ve pozisyonları, ataleti ve kuvvetlerin eksenler üzerinde oluşturduğu momentleri değiştirmektedir. Bunlar Tablo 2'de verildi. $\mathrm{Bu}$ durum sistemin kararlılığını ve kontrolcünün değişikliğine sebep olmaktadır.

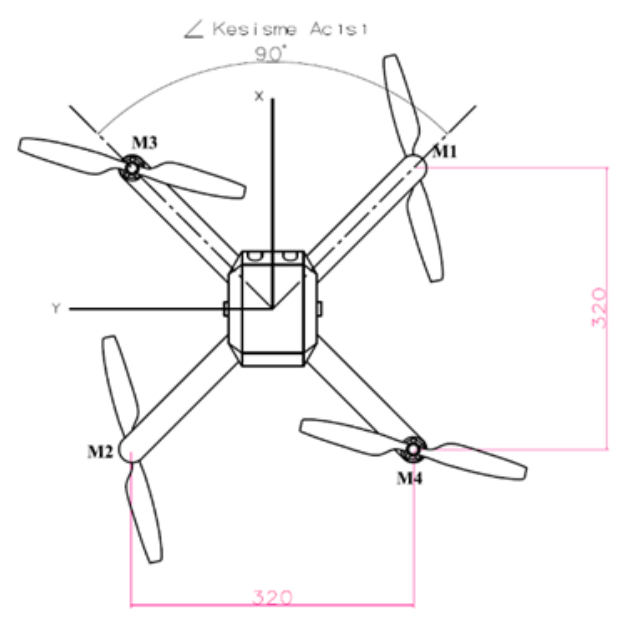

Şekil 5. X1 Konfigurasyon Kesişme Açısı 90 (Pervane Hariç Geometrik Ölçü)

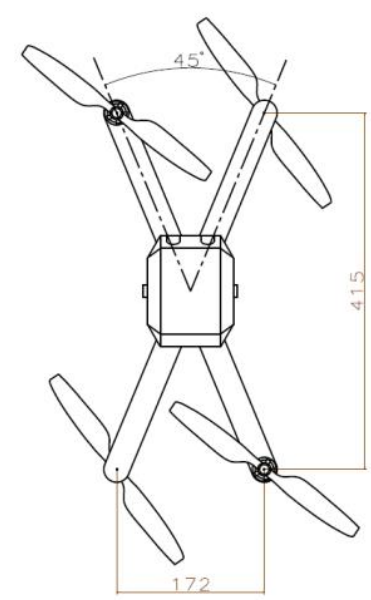

Şekil 6. X2 Konfigurasyon Kesişme Açısı $45^{\circ}$ (Pervane Hariç Geometrik Ölçü)

Tablo 2. X1 ve X2 Konfigurasyon Geometrileri

\begin{tabular}{|l|l|l|l|l|}
\hline Sembol & Tanım & X1 Konfig. & X2 Konfig. & Birim \\
\hline$L$ & Kesişim Açısı & 90 & 45 & derece \\
\hline $\mathrm{m}$ & Hava aracı kütlesi & 750 & 750 & $\mathrm{gr}$ \\
\hline $\mathrm{l}$ & Kol Uzunluğu & 0.45 & 0.45 & $\mathrm{~m}$ \\
\hline $\mathrm{lx}$ & Boy & 0.32 & 0.415 & $\mathrm{~m}$ \\
\hline $\mathrm{ly}$ & Genişlik & 0.32 & 0.172 & $\mathrm{~m}$ \\
\hline $\mathrm{I}_{\mathrm{x}}$ & Atalet Momenti, X Ekseni & 0.0064 & 0.001849 & $\mathrm{Kgm}^{2}$ \\
\hline $\mathrm{I}_{\mathrm{y}}$ & Atalet Momenti, Y Ekseni & 0.0064 & 0.01076 & $\mathrm{Kgm}^{2}$ \\
\hline $\mathrm{I}_{\mathrm{z}}$ & Atalet Momenti, Z Ekseni & 0.01265 & 0.01265 & $\mathrm{Kgm}^{2}$ \\
\hline
\end{tabular}

\subsection{Sistem Modelleme}

Döner kanatlı insansız hava aracının 6 serbestlik dereceli bir sistemdir. $\mathrm{Bu}$ değişkenlerden yuvarlanma (roll), yunuslama (pitch), yalpalama (yaw), dünya sabit eksen ile gövdeye ağırlık merkezine ilişkilendirilmiş ekseni arasında bulunan euler açılarıdır. Gövde çerçevesi üzerinde $\mathrm{p}$, q ve $\mathrm{r}$ açısal hızlarıdır. Sabit eksende konum değişkenleri; $\mathrm{x}, \mathrm{y}$ ve $\mathrm{z}$ dir. Gövde üzerinde çizgisel hızı veren $\mathrm{u}, \mathrm{v}$ ve $\mathrm{w} \operatorname{dir}[11]$.

\subsubsection{Doğrusal Dinamik Hareket}

Hava aracina uygulanan kuvvet ve momentler gövde üzerinde tanımlanmaktadır. Eşitlik 1 de verilen Newton 2. Yasası ile tanımlanır. Momentumdaki değişim kuvveti verir. Hava aracının ivme değerlerinden Fx, Fy, Fz elde edilir[12].

$$
\mathrm{F}=\mathrm{ma}
$$


Gövde eksen takımı ile dünya sabit eksen takımı arasında ilişki rotasyon ilişkisi kurularak [u, v, w] doğrusal hız bileşenleri elde edilir. Hava aracının doğrusal hızı;

$$
\frac{d}{d t}\left[\begin{array}{l}
x \\
y \\
Z
\end{array}\right]=\mathrm{s}\left[\begin{array}{l}
u \\
v \\
w
\end{array}\right] ; \quad \mathrm{v}=[\mathrm{u} v \mathrm{w}]^{\top}
$$

Hava aracı üzerine etkiyen kuvvet, açısal hız ve çizgisel hızlarla ilişkilidir.

$$
\begin{gathered}
\vec{F}=m \frac{d V}{d t} \quad \vec{F}=m\left(\dot{\overrightarrow{V^{B}}}+\overrightarrow{\Omega^{B}} x \overrightarrow{V^{B}}\right) \\
\vec{F}=m\left(\left[\begin{array}{c}
\dot{u} \\
\dot{v} \\
\dot{w}
\end{array}\right]+\left[\begin{array}{c}
p \\
q \\
r
\end{array}\right] x\left[\begin{array}{c}
u \\
v \\
w
\end{array}\right]\right)
\end{gathered}
$$

\subsubsection{Açısal Dinamik Hareket}

Sistemin açısal hareketleri, eksenler etrafindaki kuvvet farklarından oluşur. Kuvvet farkları momentleri oluşturur, bunlar Mx, My, Mz dir. Euler açılarının türevi, açısal hızı ve bunların türevi açısal ivmeyi verir [12].

$$
M=I \alpha
$$

Euler açıları ile açısal hız arasında Eşitlik 6'da ilişkilendirildi. Hava aracının açısal hızı;

$$
\frac{d}{d t}\left[\begin{array}{l}
\emptyset \\
\theta \\
\varphi
\end{array}\right]=\mathrm{S}\left[\begin{array}{l}
p \\
q \\
r
\end{array}\right] ; \omega=[\mathrm{p} \mathrm{q}]^{\top}
$$

Hava aracının açısal ivmesi;

$$
M=I \frac{d}{d t} \omega \Rightarrow\left[\begin{array}{c}
\dot{p} \\
\dot{q} \\
\dot{r}
\end{array}\right]=\frac{M}{I}
$$

Kütle merkezine uygulanan hava aracının dinamiği NewtonEuler formalizmi Eşitlik 8'de verildi.

$$
\left[\begin{array}{cc}
m_{3 x 3} & 0 \\
0 & I
\end{array}\right]\left[\begin{array}{l}
\dot{V} \\
\dot{\omega}
\end{array}\right]+\left[\begin{array}{c}
\omega x m V \\
\omega x I V
\end{array}\right]=\left[\begin{array}{c}
F \\
M
\end{array}\right]
$$

Aerodinamik kuvvetler ve momentler, momentum ve kanat elemanı teorisinden elde edildi.

$$
F_{i}=\frac{1}{2} \rho A C_{t}\left(r \Omega_{i}\right)^{2} \quad i=1,2,3,4
$$

Pervanenin alanını $A$ ile, havanın yoğunluğunu $\rho$ ile, aerodinamik katsayıyı $C t$ ile, pervanenin yarıçapı $r$ ile, pervanenin dönme hızı $\Omega i$ ile tanımland. Aerodinamik kuvvet pervane devir sayısı ve pervane yarıçapının çarpımının karesi ve diğer katsayılardan elde edilen b katsayısının çarpımından elde edilir.

$$
F_{i}=b \omega_{i}^{2} ; \mathrm{i}=4
$$

Pervane ve rotorun açısal hızının karesi ve moment katsayısı d'den pervanelerin ürettiği sürükleme momenti elde edilir.

$$
T_{i}=d \omega_{i}^{2} ; \mathrm{i}=4
$$

Döner kanatlı hava aracı dört rotor ve pervaneye sahiptir, toplam kuvvet itkiyi verir, U1 ile tanımlanır.

Itki:

$$
U_{1}=b\left(\omega_{1}^{2}+\omega_{2}^{2}+\omega_{3}^{2}+\omega_{4}^{2}\right)
$$

Rotorların farklı dönüş hızları neticesinde yuvarlanma, yunuslama ve sapma hareketlerini gerçekleştirir, U2, U3, U4 ile tanımlanır.

$$
\begin{array}{ll}
\text { Yuvarlanma: } & \mathrm{U}_{2}=\mathrm{bl} / \sqrt{2}\left(-\omega_{1}{ }^{2}+\omega_{2}{ }^{2}+\omega_{3}{ }^{2}-\omega_{4}{ }^{2}\right) \\
\text { Yunuslama: } & \mathrm{U}_{3}=\mathrm{bl} / \sqrt{2}\left(\omega_{1}{ }^{2}-\omega_{2}{ }^{2}+\omega_{3}{ }^{2}-\omega_{4}{ }^{2}\right) \\
\text { Sapma: } & \mathrm{U}_{4}=\mathrm{d}\left(\omega_{1}{ }^{2}-\omega_{2}{ }^{2}-\omega_{3}{ }^{2}-\omega_{4}{ }^{2}\right)
\end{array}
$$

\subsection{Sistem Kontrol}

İtme ve sürükleme katsayılarının sabit olduğu ve hava aracı havada asılı pozisyonda kabul edilerek kontrol tasarımının modeli basitleştirildi. Sistem, durum uzayı biçiminde U giriş vektörü ve $X$ durum vektörü ile $\dot{X}=f(X, U)$ yazılabilir[15].

$$
X=[\varnothing \dot{\varnothing} \theta \dot{\theta} \varphi \dot{\varphi} z \dot{z} x \dot{x} y \dot{y}]
$$

\begin{tabular}{|l|l|}
\hline$x_{1}=\emptyset$ & $x_{7}=z$ \\
\hline$x_{2}=\dot{x}_{1}=\dot{\emptyset}$ & $x_{8}=\dot{x}_{7}=\dot{z}$ \\
\hline$x_{3}=\theta$ & $x_{9}=x$ \\
\hline$x_{4}=\dot{x}_{3}=\dot{\theta}$ & $x_{10}=\dot{x}_{9}=\dot{x}$ \\
\hline$x_{5}=\varphi$ & $x_{11}=y$ \\
\hline$x_{6}=\dot{x}_{5}=\dot{\varphi}$ & $x_{12}=x_{11}=\dot{y}$ \\
\hline
\end{tabular}

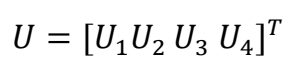

$$
\left[\begin{array}{l}
U_{1} \\
U_{2} \\
U_{3} \\
U_{4}
\end{array}\right]=\left[\begin{array}{cccc}
b & b & b & b \\
\frac{-l b}{\sqrt{2}} & \frac{l b}{\sqrt{2}} & \frac{l b}{\sqrt{2}} & \frac{-l b}{\sqrt{2}} \\
\frac{l b}{\sqrt{2}} & \frac{-l b}{\sqrt{2}} & \frac{l b}{\sqrt{2}} & \frac{-l b}{\sqrt{2}} \\
d & d & -d & -d
\end{array}\right]\left[\begin{array}{c}
\omega_{1}^{2} \\
\omega_{2}^{2} \\
\omega_{3}^{2} \\
\omega_{4}^{2}
\end{array}\right]
$$

Eğer havada askıda iken bozulmalar küçükse euler açılarının değişim oranı $(\dot{\emptyset}, \dot{\theta}, \dot{\varphi})$ ve gövde açısal hızları (p, q, r) arasındaki dönüşüm matrisi, bütünlük matrisi olarak kabul edilebilir ve $(\dot{\emptyset}, \dot{\theta}, \dot{\varphi}) \approx(\mathrm{p}, \mathrm{q}, \mathrm{r})$ yazılabilir.

$$
f(X, U)=\left(\begin{array}{c}
\dot{\emptyset} \\
\dot{\phi} \varphi\left(I_{y y}-I_{z z}\right) / I_{x x}+\dot{\phi} J_{r} \Omega_{r} / I_{x x}+l U_{2} / I_{x x} \\
\dot{\theta} \\
\varnothing \theta\left(I_{z z}-I_{x x}\right) / I_{y y}-\emptyset J_{r} \Omega_{r} / I_{y y}+l U_{3} / I_{z z} \\
\dot{\varphi} \\
\theta \emptyset\left(I_{x x}-I_{y y}\right) / I_{z z}+U_{4} / I_{z z} \\
\dot{z} \\
g-(\cos \emptyset \cos \theta) \frac{1}{m} U_{1} \\
\dot{x} \\
(\cos \emptyset \sin \theta \cos \varphi+\sin \emptyset \sin \varphi) \frac{1}{m} U_{1} \\
\dot{y} \\
(\cos \emptyset \sin \theta \sin \varphi-\sin \emptyset \cos \varphi) \frac{1}{m} U_{1}
\end{array}\right)
$$


Sistem, serbestlik derecesi sayısının sistemin girdilerinden daha fazla olan bir sistemdir. Dört rotorlu hava aracı altı serbestlik derecesine sahiptir ancak sadece dört rotoru vardır. Bu nedenle, iki serbestlik derecesi diğerlerine bağlıdır. Yuvarlanma ve yunuslama açısı değiştirildiğinde, itme vektörünün yatay bir bileşeni elde edilir, bu da sistemi X - Y düzleminde hareket ettirmeyi mümkün k1lar.

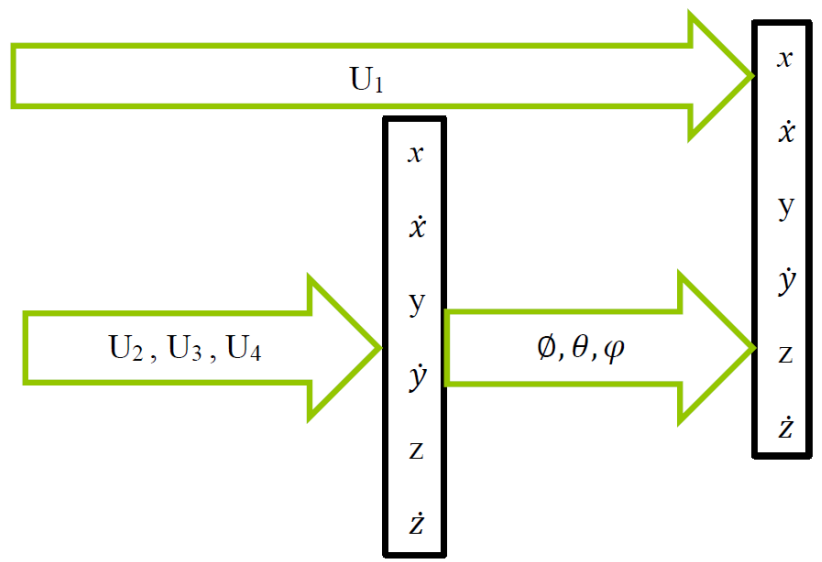

Şekil 7. Dört Rotorlu Hava Aracının Dinamikleri

\subsection{PID Denetimi}

Hava aracının havadayken maruz kaldığı gürültüler ve komutların istenilen hareketleri gerçekleştirmesi için kontrolcüye ihtiyaç vardır. Kararsız ve doğrusal olmayan sistemdir. Kontrolü için PID kontrolcü tercih edildi. Sistemin kalıcı durum tepkisine ve geçici durum tepkisine etkili olduğu ve bunu PID, hata sinyalini işleyerek yeni bir sinyal üretir, sağlar. Oransal, sistemin hata sinyalini güçlendirip zayıflatır. İntegral, sistemin cevabını yavaşlatır. Türev ise değişim ile ilgilidir, geçici durum tepkisini kisaltır [15].

Doğrusal olan ve doğrusal olmayan sistemler için etkili bir denetleyicidir. Bilinmeyen ve matematiksel olarak modellenemeyen sistemleri, sadece denetleyicideki katsayıları ayarlanarak denetlenebilir hale getirilmesini sağlar. PID denetleyicisinin yapısı ve denetim kuralı Şekil 8' de verildi.

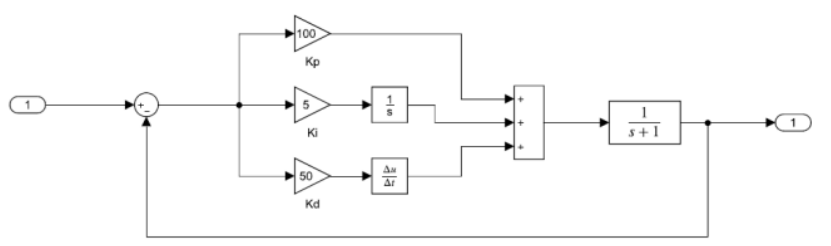

\section{Şekil 8. PID Yapısı}

\subsubsection{Yükseklik Denetimi}

Döner kanatlı hava aracı arzu edilen yüksekliğe ulaşana kadar rotorların dönüş hızları denetleyicinden gönderilen sinyaller tarafından kontrol edilir. Eşitlik 18'de yükselme ve havada asılı kalma ile ilgili durum MATLAB programında incelendi. Hava aracı yükseklik kontrolünde PID kontrolcü kullanıldı. $\mathrm{P}=50$ hava aracının hızlı bir şekilde yükselmesini sağladı. I=5; hava aracının belirlenen yüksekliğe yaklaştıkça daha yavaş hareket etmesini ve dengede kalmasını sağladı. $\mathrm{D}=50$; hava aracının yükselme sırasında oluşacak hız değişimlerini ve kontrol kaybının önlenmesini sağladı.

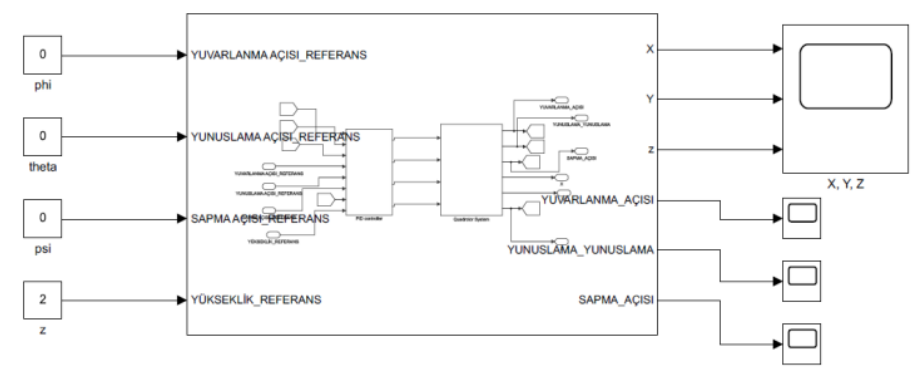

Şekil 9. Kontrolcü Blok Diyagramı

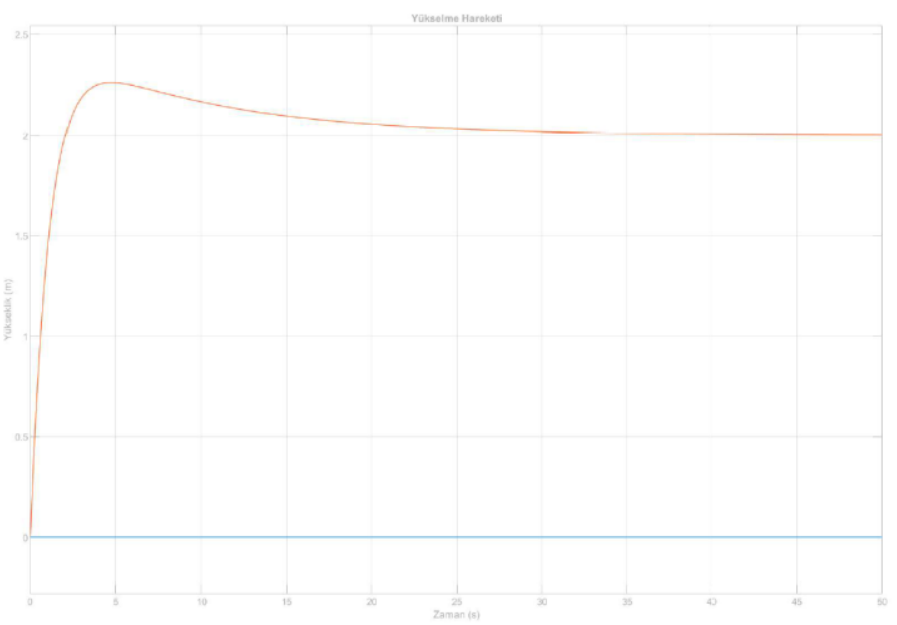

Şekil 10. Yükseklik Hareketlenme Simulasyon Sonuçları $(P=50$, $I=5, D=50$ )

Şekil 11. Yükseklik Hareketlenme Simulasyon Sonuçları $(P=50$, $I=5, D=5$ )

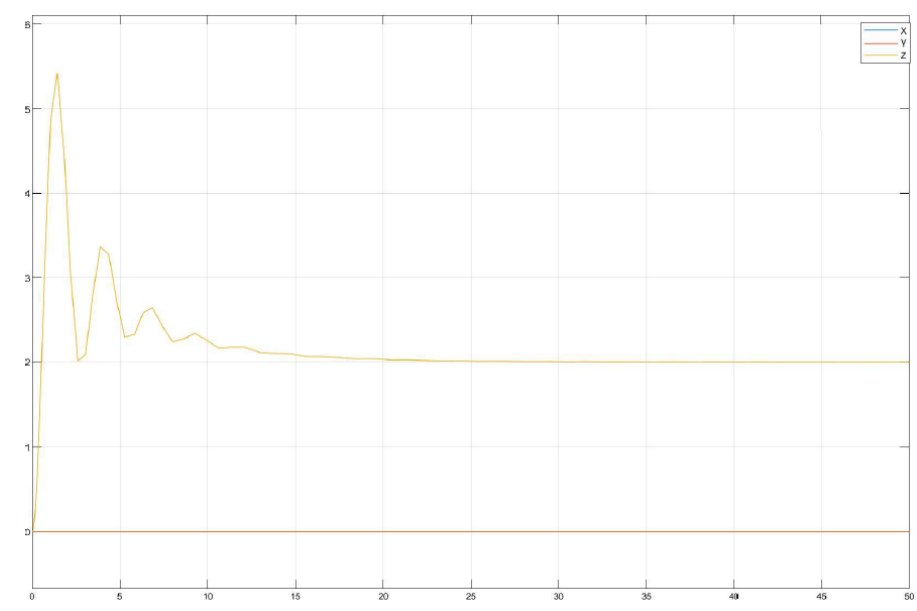


Şekil 12. Yükseklik Hareketlenme Simulasyon Sonuçları ( $P=5$, $I=1, D=1$ )

\section{Sonuçlar}

$\mathrm{Bu}$ çalışmada döner kanatlı dört rotorlu hava aracının dinamikleri incelendi. Bir PID kontrolcü, asılı uçarken hava aracına iyi adapte olduğu simülasyon çalışmalarında doğrulandı. O. Köse ve T. Oktay'ın çalışmasında yükseklik kontrolü için kullanılan PID katsayıları; [50,5,50] verilmiştir[14]. Bu çalışmada da elde edilen scope verisi (Şekil 10) eşdeğer veriler elde edilmiştir. Farklı PID değerlerinden elde edilen veriler paylaşıldı (Şekil 11-12). PID denetleyicisi, hava aracını havada asılı kaldığında ve atmosferik gürültülerin olmadığı durumlarda kontrol edebildi. P değeri sabit ve diğer değerlerin değiştirilmesi farklı sonuçlara sebep oldu. I'nın farklı değerlerde aşım ve yerleşme zamanı arttığı ve yükselme zamanı azaldığı görüldü. D' nin farklı değerlerde aşım ve yerleşme zamanı azaldığı görüldü.

Hava aracının kolları arasındaki kesişim açısının değişmesi ile yanal daralma sonucunda X1 (Kesişim açıs1 90)'den X2 (Kesişim açısı $45^{\circ}$ ) konfigürasyona geçişi sağlandı. $Z$ ekseni boyunca hareket, eşitlik 12 'de verilen itki denkleminde doğrusal hareket gerçekleştirmektedir. Yükselme süresi ve oturma süresi yaklaşık değerler elde edildi. Şekil değişikliğinin simülasyon çıktılarında herhangi bir değişikliğe sabep olmadığ görülmektedir. Simülasyon çalışması rüzgar hızının olmadığı ortamda gerçekleştirildi. Gelecek çalışmalarda hava aracının konfigürasyon değişimlerinde ileri hareket ve yanal hareket incelenecektir.

\section{Kaynakça}

[1] Desbines, A., Expert, F., Boyron, M., Diperi, J., Viollet,S., Ruffier, F. (2017). X-Morf: A crash-separable quadrotor that morfs its X-geometry in flight. 2017 Workshop on Research, Education and Development of Unmanned Aerial Systems (RED UAS)

[2] Falanga, D., Kleber, K., Mintchev, S., Floreano, D., Scaramuzza, D. (2018) The Foldable Drone: A Morphing Quadrotor that can Squeeze and Fly. IEEE Robotics And Automation Letters. Preprint Version. Accepted November, 2018

[3] Bai, Y., Gururajan, S. (2019). Evaluation of a Baseline Controller for Autonomous "Figure-8" Flights of a Morphing Geometry Quadrotor: Flight Performance. Drones 2019, 3, 70

[4] Di Luca M, Mintchev S, Heitz G, Noca F, Floreano D. (2017). Bioinspired morphing wings for extended flight envelope and roll control of small drones. Interface Focus 7: 20160092.

[5] Prisacariu, V., Sandru, V., \& Rău, C. (2011). Introduction morphing technology in unmanned aircraft vehicles (UAV). Paper presented at the International Conference of Scientific Paper, AFASES.

[6] Oktay, T., \& Sal, F. (2016). Combined passive and active helicopter main rotor morphing for helicopter energy save. Journal of the Brazilian Society of Mechanical Sciences and Engineering, 38(6), 1511-1525

[7] T.Oktay and K. Oğuz, "Non Simultaneous Morphing System Design for Yaw Motion in Quadrotors," Journal of Aviation, vol. 3, no. 2, pp. 81-88, 2019.
[8] O. Kose and T. Oktay, "Dynamic Modeling and Simulation of Quadrotor for Different Flight Conditions," European Journal of Science and Technology, no. 15, pp. 132-142, 2019

[9] O. Köse and T. Oktay, "Non Simultaneous Morphing System Desing for Quadrotors," Avrupa Bilim ve Teknoloji Dergisi, no. 16 , pp. 577-588,2019.

[10] J. Zhang, J. Feng, B. Zhou. Sensor-Fusion-Based Trajectory Reconstruction for Quadrotor Drones

[11] Pamadi B. (2004) Performance, stability, dynamics, and control of airplanes. Reston, VA: AIAA.

[12] B. L. Stevens, F. L. Lewis(2003). Aircraft control and simulation, Third Edition. J. Wiley, New Jersey, 2003.

[13] K. Nonami, F. Kendoul, S. Suzuki, W. Wang, D. Nakazawa.(2010) Autonomous Flying Robots. Springer Tokyo Dordrecht Heidelberg London New York

[14] Köse,O., Oktay,T.(2021) İnovatif Yöntemlerle Kuadkopter Modellenmesi, Kontrolü Ve Gerçek Zamanlı Uygulamaları. Doktora Tezi, Erciyes Üniversitesi, Fen Bilimleri Enstitüsü, KAYSERİ, 2021

[15] Randal W. Beard. (2015). Quadrotor Dynamics and Control. Brigham Young University. February 19, 2008

[16] Robert C. Leishman, John Macdonald, Randal W. Beard, Timothy W. McLain. Quadrotors \& Accelerometers State Estimation with an Improved Dynamic Model. IEEE Control Systems Magazine. February 2014 